\title{
Chapter 8 \\ Modelling Risk Reduction Measures \\ to Minimise Future Impacts of Storms \\ at Coastal Areas
}

\author{
Óscar Ferreira
}

\begin{abstract}
Coastal storms often cause damages and losses in occupied areas. Under climate change conditions (i.e. sea-level rise and increased frequency of extreme sea levels) and increasing human occupation, the consequences of coastal storms will be amplified if no adaptation actions are implemented. The selection of the best possible coastal management measures to reduce risks at coastal areas, considering costs, effectiveness and acceptance, will be mandatory in the future. This work presents a generic approach to model disaster risk reduction measures at coastal areas, including climate change effects. The proposed methodology is adaptable to any coastal region and can be used to test (and improve) management options at a broad number of coastal areas. It can also be used to define a timeframe for the implementation of the defined measures since not all risk reduction measures, under a climate change scenario, need to be implemented at the same time. This would help to optimise implementation costs while reducing the risk to the occupation and people.
\end{abstract}

Keywords Coastal hazards $\cdot$ Climate change $\cdot$ Preparedness $\cdot$ Coastal management

\section{Introduction}

Storms impacting sandy coastal areas produce hazards such as erosion and inundation that, in turn, promote risk to life and property damage in occupied areas, and the alteration and/or fragmentation of habitats (Ferreira et al. 2017). Coastal damages and risks are expected to increase in the near future not only in association with climate change (e.g. sea-level rise (SLR), change in frequency and magnitude of storms) but also due to increasing human occupation in coastal areas (e.g. van Dongeren et al. 2018). In the next decades, SLR will likely become the dominant driver in erosion/flooding risk at coastal areas and may escalate that risk by up to $300 \%$ over the next 3 decades (Wahl and Plant 2015). Because of climate change, Vousdoukas et al. (2018a) project an increase of the global average 100-year extreme sea levels

\footnotetext{
Ó. Ferreira $(\bowtie)$

Universidade do Algarve, CIMA, FCT, Faro, Portugal

e-mail: oferreir@ualg.pt
} 
between 2000 and 2100 of 58-172 cm. Considering existing trends in shoreline dynamics, combined with coastal recession driven by sea-level rise, Vousdoukas et al. (2020a) estimate a total retreat exceeding $100 \mathrm{~m}$ for almost half of the world's sandy beaches, by the end of the century.

In Europe, the expected annual damage due to coastal floods is expected to increase by three orders of magnitude by the end of the century if no adaptation is taken (Vousdoukas et al. 2018b). By the 2080s, between 13 and 123 million additional people will face annual coastal floods worldwide, assuming no upgrade in adaptation measures for an additional SLR between $0.19 \mathrm{~m}$ and $0.68 \mathrm{~m}$ (Brown et al. 2019). By 2100, without adaptation, $0.2-4.6 \%$ of the global population is expected to be flooded annually under $25-123 \mathrm{~cm}$ of global mean SLR, with expected annual losses of $0.3-9.3 \%$ of the global gross domestic product (Hinkel et al. 2014).

With this view of the future, coastal authorities need to assess the level of impact and the risk in their coastal zones and implement tested and feasible Disaster Risk Reduction (DRR) and PMP (prevention, mitigation and preparedness) measures (van Dongeren et al. 2018). Considering that a substantial proportion of the threatened coastal areas are in densely populated areas, there is a need for the design and implementation of effective adaptive measures (Vousdoukas et al. 2020a). For that purpose it is paramount to first test and validate those measures, analysing their effectiveness and choosing the optimal ones (higher effectiveness for lower cost). That can be done by implementing such measures at existing models and simulating their response and behaviour to coastal storms under climate change scenarios. This paper presents and discusses models and approaches to test DRR measures and their effectiveness in minimising the impacts of coastal storms at occupied areas.

\section{Modelling the Impact of Coastal Storms}

Coastal retreat and flooding can be estimated by using simple formulations or models. For overwash assessment, the most commonly used method is to estimate runup using empirical formulations that require offshore wave conditions and beach slope. The computed runup can be added to a given sea level and compared with the existing morphology to estimate the overwash potential, depth and/or extension. For coastal inundation, bathtub approaches are still often used, simply comparing the estimated sea level (for a given return period) with the morphology or occupation elevation. The storm-induced retreat/erosion can also be computed by using relatively simple analytical models (e.g. Larson et al. 2004; Mendoza and Jiménez 2006). These models use relatively simple formulations that integrate driving mechanisms (such as wave height, storm duration and sea level) jointly with the morphological and sedimentological characteristics of the coastal area (e.g. dune height, berm width, beach slope or grain size). Such simple methods have, however, several limitations, mainly at complex environments, such as engineered coastlines or areas with complex geomorphology. Furthermore, the hazard and consequent risk can change due to feedback mechanisms. The lowering of a dune by overwash will lead to an increase in the 
hazard when compared with the initial situation/morphology. These feedback mechanisms can also occur differently alongshore, as a function of morphological variability. In cases where feedback mechanisms may be highly relevant, simple models and formulations may not fully reflect the impacts associated with a given event. In those cases, process-based models with high-resolution topo-bathymetric grids, after validation and calibration, may be helpful to better understand the hazard in coastal areas (Ferreira et al. 2017).

Process-based models, like XBeach (Roelvink et al. 2009), can be employed to determine both coastal erosion and flooding, for all regimes and with great detail but requiring a higher level of computational complexity and available data for model calibration. Process-based models reproduce the processes occurring on coastal areas during a storm, containing the essential physics of dune erosion, overwash, avalanching, swash, infragravity waves and wave groups. Inundation models, such as LISFLOOD (Bates and De Roo et al. 2000), which account for lateral connectivity and permeability, can also be used to better represent the inundation area. Thus, the recommended models to determine the hazard associated with episodic erosion and/or flooding are open-source process-based nearshore storm impact models such us XBeach (for erosion and overwash) or XBeach coupled with the LISFLOOD (for marine flooding). These models have been applied to a vast number of diverse coastal areas and have extensive use and validation, providing confidence in their application (Ferreira et al. 2018).

Process-based models make use of complex-modelling techniques and require a high amount of data. They can be used on a stand-alone basis, but are normally integrated within a more complex processing scheme that includes data import from external sources, data processing, perform the runs, data post-processing and simplification and final results exportation. For the mentioned scheme, model trains are often developed (see example at Ferreira et al. 2018), starting from the incorporation of available data from other operational systems and downscaling storm conditions to local hazards. They should take into consideration, on their implementation, the availability of suitable regional data sources or forecast systems, the dominant physical and morphological conditions that control the storm processes, the selected onshore hazards to be modelled, and the selected receptors to be impacted. In the case of modelling climate change, they must also take into consideration the existence of adequate regional or local climate change predictions to be incorporated as input values. The results of the high-resolution hazard models are translated into impact using damage curves or any other relationship that relates hazard with the damage at the receptors. 


\section{Modelling Risk Reduction Measures Including Climate Change}

When considering the impact of climate change at coastal areas, most of the current approaches assume that the existing morphology and occupation will be maintained and only the forcing conditions will change (e.g. Vousdoukas et al. 2018a; Brown et al. 2019). Recent works often use simple approaches to adaptation (e.g. vertically rising dykes, Vousdoukas et al. 2020b) and do not run computational demanding morphodynamic models. Only rarely DRR measures are fully modelled and tested (e.g. Plomaritis et al. 2018; Ferreira et al. 2019) and even less frequently they incorporate climate change effects.

To support and aid to achieve the most informed and best possible decisions regarding risk prevention, models can be used to simulate and evaluate the effectiveness of current and potential future DRR measures under storm conditions and even climate change. This is achieved by simulating historical and climate changerelated storm scenarios with and without DRR measures in place (Fig. 8.1). From these simulations, it is possible to obtain predictions of local flooding and erosion, which combined with characteristics of the local population, built environment and infrastructure, allow to compute storm impact and the effectiveness of the measures. Models can also be used to evaluate how effective a DRR measure or a combination of measures will be on the reduction of the impact of storm events. Those measures can be split into different types that require different modelling approaches, as explained by Jäger et al. (2018). "Exposure-reducing measures" move receptors out of highrisk areas by temporarily evacuating people or permanently relocating residential areas. For instance, house removal (or relocation), will remove the exposed elements (reducing risks) while the computed hazard may remain the same. For these measures, receptors are removed from the model, which do not need to be rerun (Fig. 8.1), since the hazard level will be the same, for current conditions, while the risk is reduced due to the removal of the occupation. "Pathway-obstructing measures" change the morphology and hence its interactions with waves and water levels. That is the case of beach nourishment or dune recovery that obliges to introduce a new morphology and to rerun the models for all desired conditions (Fig. 8.1) since the hazard level

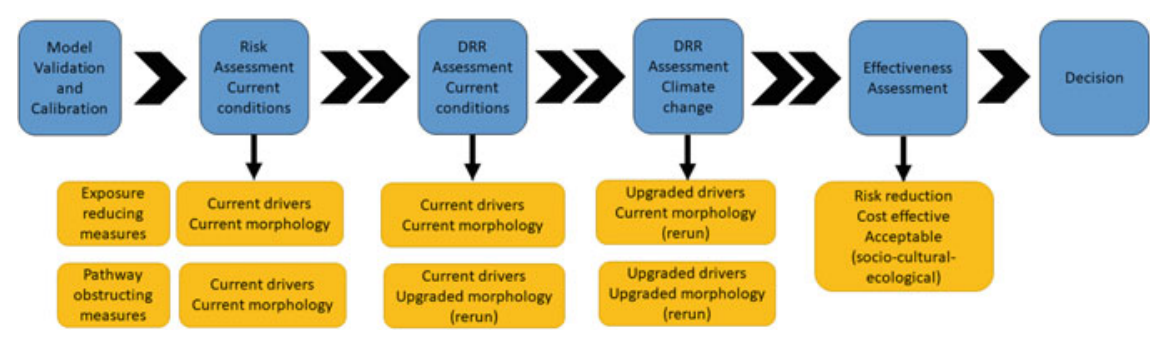

Fig. 8.1 Representation of the needed model steps from local validation and calibration until the final decision, after effectiveness assessment of the tested DRR measures 
will not be maintained. The third type of DRR measures is "vulnerability-reducing measures", which include flood protection for individual receptors (e.g. sandbags) or raising awareness at the population. This type of DRR measures is not easy to model, although there are attempts to assess their effectiveness (see Cumiskey et al. 2018).

The impact of predicted future climate scenarios (e.g. sea-level rise and extreme sea levels), based on available projections at the regional or local scale, under the Representative Concentration Pathway 8.5 or other adequate estimates, can be incorporated in the models to assess the future effectiveness of DRR measures. In such cases, new input variables (e.g. wave height and total sea-level for a given return period or a set of forecasted conditions for a given year in the future) will be required, depending on the chosen scenario and year (e.g. 2050, 2100), obliging to rerun the model for each defined condition (Fig. 8.1). Thus, for DRR assessment under climate change scenarios, both types of measures (exposure-reducing and pathway-obstructing) most probably imply the model's rerun.

The choice of the DRR measures to be tested should be done by expert judgment in consultation with end-users and stakeholders to ensure their future integration into management plans and to guarantee that informed and scientific-based coastal management decisions are taken. The final decision, after testing (Fig. 8.1), should consider the measured effectiveness, the social-cultural and the ecological acceptance of the measures, to ensure their sustainability and approval. For the effectiveness index (Ie) Ferreira et al. (2019) proposed the use of Eq. 8.1 for each simulated DRR:

$$
I e=100 \% x \frac{(\% \text { damagecurrentsituation }-\% \text { damagedwithDRR })}{\% \text { damagecurrentsituation }}
$$

With a zero $(0 \%)$ value meaning that the DRR measure had no benefit when compared to the current situation, while $100 \%$ indicates total risk prevention by the modelled DRR.

DRR assessment, including climate change, can be performed ex-ante, years or decades before the potential consequence, allowing for the development of the best possible DRR solution, and further testing it as time passes and new data and knowledge arises. With such an approach, the preparedness level for climate change impacts at coastal areas can be much higher than the current one, defining the most effective solution. It also allows defining at which time the solution should be implemented to optimise resources (see Fig. 8.2). Not all potential measures to minimise climate change impacts will need to be implemented at the same time or at the nearest future. Continuity of the use of models for the evaluation of DRR effectiveness would allow the definition of local timeframes for coastal management, defining the optimal management approach at each moment within the next decades. 


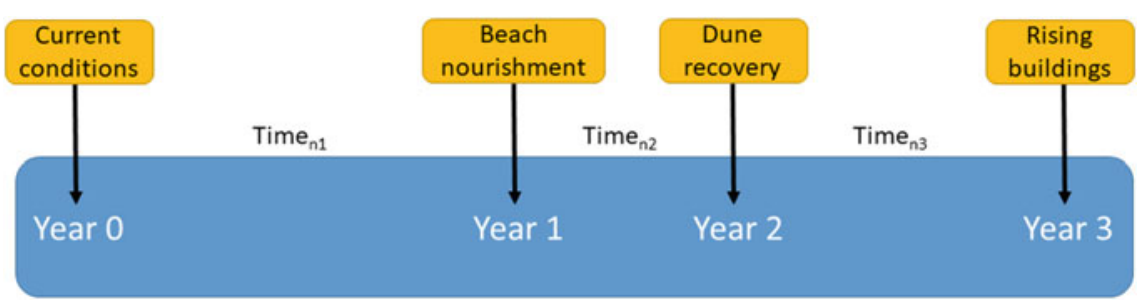

Fig. 8.2 Hypothetical timeframe for the optimal implementation of selected DRR measures, as a function of the evolution of climate change drivers

\section{Bottlenecks and Future Developments}

Modelling limitations, namely, for the more complex process-based models, include the lack of high-quality quantitative validation due to lack of data, particularly relating to water discharge, water velocities and inundation extent (Ferreira et al. 2018). Limitations on application also include the difficulty of a wide direct use by endusers, including coastal managers. The first limitation is being solved by the ongoing and increasing improvement on data access (and quality) worldwide, including online access to coastal morphology and wave/water level series, but an extra effort on field measurements is still required. To obviate the second limitation, a higher interaction will be needed on the transfer of knowledge from the coastal scientific community to end-users.

The applicability of the exposed models to define DRR measures, including climate change, will require a better determination of the vulnerability relationships between the indicators used to define damage or impact (e.g. water discharge, shoreline retreat) and the exposed elements (e.g. type of building). At the local level, to better define the vulnerability, it will be required a historical analysis of the damage promoted by other (past) events as learning lessons for the future. An extended analysis of the effectiveness of DRR measures should also be implemented, by including aspects linked to the economic value, ecosystem services and socio-cultural characteristics of each region. A cost-benefit analysis, including ecosystem services, is highly advised, to be sure that implemented DRR measures are not only effective but also less costly. Indirect impacts are also often not accounted on the use of these models. However, the full assessment of impacts should include all cascade effects. For instance, the expected increase on coastal flooding events, associated with climate change, will cause extended cascade effects, by stopping the economy of those coastal areas more often and for a longer period. Those effects are still rarely evaluated but should be incorporated in future impacts assessments. 


\section{Conclusions}

Climate change and direct consequences, like sea-level rise or changes on storminess, have been predicted for the last decades, at global, regional and local levels. It is also known that these drivers will lead to a change on impacts at coastal areas, with a general trend to increasing hazards and derived consequences. High-resolution morphodynamic numerical models also exist and have been tested, validated and improved, at coastal areas, for the last decades. A high diversity of disaster risk reduction measures have also been implemented all over the world over the last decades. It is, however, not yet common to see the joint use of morphodynamic models that integrate climate change predictions, morphodynamic models and disaster risk reduction measures to define future coastal management actions, their optimisation and their potential effectiveness against climate change impacts. This work proposes a generic approach to be followed when testing adaptation and risk reduction measures for the future, considering climate change, including the application of an effective index, among other assessments. This proposal aims to contribute to the extended use of validated coastal models, encompassing a great range of modelled conditions, including climate change, enhancing disaster preparedness for effective risk reduction at coastal areas.

Acknowledgements This work was supported by the European Union 7th Framework Programme through the grant to RISC-KIT ("Resilience increasing Strategies for Coasts-Toolkit"), contract no. 603458, and the Portuguese Science and Technology Foundation through the grants attributed to project EW-COAST (ALG-LISBOA-01-145-FEDER-028657) and CIMA (UID/MAR/00350/2013).

\section{References}

Bates PD, De Roo APJ (2000) A simple raster-based model for floodplain inundation. J Hydrol 236:5477

Brown S, Nicholls RJ, Pardaens AK, Lowe JA, Tol RSJ, Vafeidis AT, Hinkel J (2019) Benefits of climate-change mitigation for reducing the impacts of sealLevel rise in G-20 countries. J Coast Res 35(4):884-895

Cumiskey L, Priest S, Valchev N, Viavattene C, Costas S, Clarke J (2018) A framework to include the (inter)dependencies of Disaster Risk Reduction measures in coastal risk assessment. Coast Eng 134:81-92

van Dongeren A, Ciavola P, Martinez G, Viavattene C, Bogaard T, Ferreira O, Higgins R, McCall R (2018) Introduction to RISC-KIT: resilience-increasing strategies for coasts. Coast Eng 134:2-9

Ferreira O, Plomaritis TA, Costas S (2017) Process-based indicators to assess storm induced coastal hazards. Earth-Sci Rev 173:159-167

Ferreira O, Plomaritis TA, Costas S (2019) Effectiveness assessment of risk reduction measures at coastal areas using a decision support system: findings from Emma storm. Sci Total Environ 657:124-135

Ferreira O, Viavattene C, Jiménez JA, Bolle A, das Neves L, Plomaritis TA, McCall R, van Dongeren AR (2018) Storm-induced risk assessment: evaluation of two tools at the regional and hotspot scale. Coast Eng 134:241-253 
Hinkel J, Lincke D, Vafeidis AT, Perrette M, Nicholls RJ, Tol RSJ, Marzeion B, Fettweis X, Ionescu C, Levermann A (2014) Coastal flood damage and adaptation costs under 21st century sea-level rise. PNAS 2014(111):3292-3297

Jäger WS, Christie EK, Hanea AM, den Heijer C, Spencer T (2018) A Bayesian network approach for coastal risk analysis and decision making. Coast Eng 134:48-61

Larson M, Erikson L, Hanson H (2004) An analytical model to predict dune erosion due to wave impact. Coast Eng 51:675-696

Mendoza ET, Jiménez JA (2006) Storm-induced beach erosion potential on the Catalonian coast. J Coast Res SI 48:81-88

Plomaritis TA, Costas S, Ferreira Ó (2018) Use of a Bayesian Network for coastal hazards, impact and disaster risk reduction assessment at a coastal barrier (Ria Formosa, Portugal). Coast Eng 134:134-147

Roelvink D, Reniers A, van Dongeren AP, de Vries JVT, McCall R, Lescinski J (2009) Modelling storm impacts on beaches, dunes and barrier islands. Coast Eng 56:1133-1152

Vousdoukas MI, Mentaschi L, Voukouvalas E, Bianchi A, Dottori F, Feyen L (2018) Climatic and socioeconomic controls of future coastal flood risk in Europe. Nat Clim Chang 8:776-780

Vousdoukas MI, Mentaschi L, Voukouvalas E, Verlaan M, Jevrejeva S, Jackson LP, Feyen L (2018) Global probabilistic projections of extreme sea levels show intensification of coastal flood hazard. Nat Commun 9:2360

Vousdoukas MI, Ranasinghe R, Mentaschi L, Plomaritis TA, Athanasiou P, Luijendijk A, Feyen L (2020) Sandy coastlines under threat of erosion. Nat Clim Change 10:260-263

Vousdoukas MI, Mentaschi L, Hinkel J, Ward PJ, Mongelli I, Ciscar J, Feyen L (2020b) Economic motivation for raising coastal flood defenses in Europe. Nat Commun 11:2119

Open Access This chapter is licensed under the terms of the Creative Commons Attribution 4.0 International License (http://creativecommons.org/licenses/by/4.0/), which permits use, sharing, adaptation, distribution and reproduction in any medium or format, as long as you give appropriate credit to the original author(s) and the source, provide a link to the Creative Commons license and indicate if changes were made.

The images or other third party material in this chapter are included in the chapter's Creative Commons license, unless indicated otherwise in a credit line to the material. If material is not included in the chapter's Creative Commons license and your intended use is not permitted by statutory regulation or exceeds the permitted use, you will need to obtain permission directly from the copyright holder.

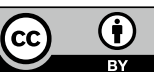

